\title{
Using a consumer choice model to explain the effect of the newly developed oxford COVID-19 government stringency measure on hotel occupancy rates
}

\author{
Azmat Gani ${ }^{1}$ (D) \\ Accepted: 12 January 2022 / Published online: 25 January 2022 \\ (c) The Author(s), under exclusive licence to Springer Nature B.V. 2022
}

\begin{abstract}
In response to the unexpected outbreak of the novel coronavirus (COVID-19), governments worldwide implemented stringent measures to contain its transmission. This study investigates the effect of the stringency of COVID-19 outbreak government measures on hotel occupancy rates in the world's top ten visitor destination countries. The analysis in this study draws upon the recently developed novel indicator, government stringency, compiled systematically by the Oxford COVID-19 Government Response Tracker for March 2020 to March 2021. By adopting a structural consumer choice model, the panel estimation procedure is applied to assess the effect of government stringency on hotel occupancy rates. The findings revealed a statistically significant adverse effect of government stringency on hotel occupancy rates. The findings suggest that although government containment measures had the desired effect of reducing transmissions of COVID-19 and a crucial predictor of hotel occupancy rates in the top ten tourist destination countries, it adversely impacted the tourism hospitality sector through reduced demand for hotel accommodation as occupancy rates plunged. This study's analysis supports the consumer choice modelling approach as it can be considered a relevant analytical framework that is satisfactorily able to explain the adverse effects of governments containment measures on hotel occupancy rates. This research contributes to the tourism modelling literature and complements previous studies in providing an additional understanding of the effect of government stringency measures based on the newly established Oxford COVID-19 Government Response Tracker Database within a coherent modelling framework.
\end{abstract}

Keywords Government stringency · Oxford tracker · Consumer choice model · International · Visitors · Hotel occupancy rates · Top ten destinations

Azmat Gani

azmat@squ.edu.om

1 Department of Economics and Finance, College of Economics and Political Science, Sultan Qaboos University, Al Khod 123, P.O. Box 20, Muscat, Oman 


\section{Introduction}

The outbreak of the novel coronavirus in 2019, now known as COVID-19, has turned into a significant pandemic (Ozturk 2021 and Koo et al. 2020), causing the loss of millions of human lives and disrupting the world's economic and social fabric. According to Barro et al. (2020), this pandemic poses the most significant threat to humankind and the global economy since the Spanish Flu of 1918, while Pileggi (2021) notes the pandemic as one of the most traumatic events of recent times. Following its identification and possible origin of location in China, COVID-19 has crossed the boundaries of almost every nation worldwide. According to the World Health Organisation, as of January 7, 2022, the worldwide confirmed cases of COVID-19 infections reached 298,915,721, deaths of 5,469,303 people and 9,118,223,397 vaccine doses administered. Other than the unprecedented levels of death, the pandemic has resulted in severe contractions in economic activities, including disruptions to societies lifestyles. As of December 2021, populations around the globe continue to bear severe health, social and economic impacts of this disease, with very few countries revealing signs of a speedier recovery that matches the pre-pandemic (2019 and before) levels of the state of economies.

Among other economic activities worldwide, the world's tourism industry has taken a brutal hit from the COVID-19 pandemic. For instance, according to the United Nations World Tourism Organisation (https://www.unwto.org/tourism-statistics-data), international tourist arrivals worldwide declined by between 70 to 75 percent in 2020 from the preceding year. By January 2021, the drop was even more severe than the preceding years, reported to be around 87 percent, mainly due to international border closures that restricted global travel. The economic effect across the world is apparent waves of contractions in economic growth, foreign exchange earnings and job creation. The recent compilation of statistics from the World Travel and Tourism Council revealed that, before the pandemic, the world's travel and tourism sector contributed 10.6 percent of all jobs, 10.4 percent of global gross domestic product (GDP), and international visitor spending approximately 6.8 percent of total exports.

A year onwards from the pandemic, severe declines in economic activities across the globe has become apparent. For example, in 2020, the World Travel and Tourism Council statistics confirm that the travel and tourism sector contributed 5.5 percent of world GDP, with 272 million employed globally (compared to 334 million in 2019), with international visitor spending plummeting by an unprecedented 69.4 percent. Massive contractions in economic activity have been observed in many tourisms' dependent countries. As a result, economic growth in many countries plummeted in 2020, with the declining trend continuing into 2021. For example, growth statistics compiled by the International Monetary Fund (April 2021) revealed that, in 2020, the world economy contracted by -3.3 per cent. The worldwide tourism industry has been one of the worst affected economic sectors due to the government-imposed bans on international travel and border closures to contain the transmission of COVID-19. As a result, the global tourism sector suffered an estimated loss of \$1.3 trillion (United Nations Conference of Trade and Development, 19 March 2021).

Across the globe, the tourism sector has grown into vital production sectors, exclusively generating incomes, absorbing the domestic labour, and connecting other sectors of the economy. Pileggi (2021) argued that economic oriented priorities correspond to positive performance and the tourism sector's past positive contributions to nations development confirm this. Tourism interlinkages with other production sectors within a country generate a strong multiplier, allowing the growth of other tourism linked sectors, promoting the 
growth and development of business outside its core. Exponential increases in COVID-19 deaths worldwide day by day (Osseni 2020) triggered both governments to continue instituting more stringent containment measures. As a result, worldwide international arrivals dropped sharply because international travel restrictions strengthened (Chen et al. 2021). It has been evident that the tourism sector suffered adverse effects as most countries instituted disease containment policies such as short and long-term international border closures and in-country lockdowns to control the virus's transmission (Maier and Brockmann 2020). This resulted in the industry taking an unprecedented brunt of the pandemic with the closure of several businesses directly serving tourists and those externally connected to tourism services.

However, the containment measures varied from country to country across the world. According to the newly compiled and comprehensive data on government containment measures (henceforth referred to government stringency) from the Oxford Covid-19 Government Response Tracker (https://www.bsg.ox.ac.uk/research/research-projects/covid-19government-response-tracker), among the top ten international visitor recipient countries (China, France, Germany, Italy, Mexico, Spain, Thailand, Turkey, United Kingdom, and the United States), for March 2020 to March 2021, average stringency index values in these countries ranged from 58.0 in Thailand (least stringent) to 74.6 in the United Kingdom (most stringent). Among these countries, international tourism formed an essential part of their national economy (Table 1). Before the COVID-19 pandemic, tourism contributed to over 12 per cent of their gross domestic product (GDP). According to Table 1, in 2020, on average, tourism contribution to gross domestic fell dramatically by more than 50 percent. A caveat to the data in Table 1 is that it should be interpreted with caution as the contribution to the GDP of the tourism sector is in its "extended form" (total and not directly). Although the World Travel and Tourism Council (WTTC) compiles valuable aggregate data on a range of variables, the WTTC is not part of the official statistical system. The Tourism Satellite Account (TSA) (https://www.oecd.org/cfe/tourism/tourismsatelliteacco untrecommendedmethodologicalframework.htm) provides a standard statistical framework

Table 1 Tourism contributions to national output in top ten visitor recipient countries Source: Author's computations using the World Travel and Tourism Council (https://wttc.org/Research/Economic-Impact)

\begin{tabular}{lrl}
\hline Country & $\begin{array}{l}\text { Contribution of gross domestic product } \\
(\%) \text { in } 2019\end{array}$ & $\begin{array}{l}\text { Contribution of gross } \\
\text { domestic product }(\%) \text { in } \\
2020\end{array}$ \\
\hline China & 11.3 & 4.5 \\
France & 8.5 & 4.7 \\
Germany & 9.8 & 5.5 \\
Italy & 13.1 & 7.0 \\
Mexico & 15.5 & 5.9 \\
Spain & 14.1 & 5.9 \\
Thailand & 19.7 & 8.4 \\
Turkey & 11.3 & 5.0 \\
United Kingdom & 10.1 & 4.2 \\
United States & 8.6 & 5.3 \\
Average & 12.2 & 5.6 \\
\hline
\end{tabular}

and the primary tool for the economic measurement of tourism. However, the drawback 
of accessing TSA measurements is that now not all countries produce economic measurements of tourism using the TSA framework, so homogeneous and comparable data are not available for different nations.

While government stringency had the desired effects of containing COVID-19 transmission and preventing undue stress in health professionals and health systems (Koo et al. 2020), it is most likely to have adversely impacted the demand for hotel accommodation. Across the world's tourist destinations, hotels are one of the fastest-growing services of the hospitality sector, and it employs thousands of people given their labour-intensive nature of services. Among the top ten visitor destinations, recent statistics indicate that hotel occupancy rates declined during the early part of 2020 as governments gradually introduced containment measures of different magnitudes. According to the statistics compiled by the United Nations World Tourism Organisation, there is unambiguous evidence that in the top ten visitor destination countries listed in Table 1, hotel occupancy rates falling sharply between March and May of 2020, improving towards the middle of 2020, and sliding again towards the last quarter of 2020. The downward trend in hotel occupancy has continued into 2021.

Studies providing a coherent analysis of the effects of government stringency on hotel occupancy within a reliable modelling framework is exceedingly rare. As far as the author knows, this is the first study to investigate the effect of COVID-19 related government stringency measures on hotel occupancy rates across the world's top ten visitor recipient countries using s structural consumer choice model. This study uses the novel and systematically compiled most recent and up to date government stringency measures produced by The Oxford COVID-19 Government Response Tracker (OxCGRT), discussed in detail in the next section. The panel estimation procedure is applied to the data beginning March 2020 to March 2021 for the world's top ten visitor recipient countries.

An inquiry using the most recent composite government response measures data in a coherent consumer choice modelling framework that determines the effect of government stringency on hotel occupancy among the world's top leisure tourism destination countries is sparse. Hence, this research makes a novel contribution to the literature as it provides an understanding of the effect of government stringency measures considering the COVID-19 pandemic on hotel occupancy rates using the newly established measure of government stringency.

This study adds value to the tourism and hospitality literature by engaging in an investigation that shifts attention towards the role and importance of tourism governance and specific pandemic-driven government policies and their impacts on the tourism and hotel industry within an appropriate modelling framework using a new data set. Recent studies (for example, Pileggi 2021; Ozturk 2021; Lim et al. 2021; Thirumaran et al. 2021; Costantino et al. 2020) made attempts to investigate pandemic driven government policy responses, showing how COVID-19 has impacted the tourism and hotel industry. This study complements these authors line of investigation. It offers additional contribution through examining the impacts of government measures by using a recently developed unique data set that has been rarely tested in terms of gauging government stringency. The findings of this study would enrich the tourism and hospitality empirical modelling literature and provide the necessary policy implication for the tourism and pandemic led government policy nexus. The findings benefit tourism policymakers in developing post-COVID-19 policies to improve international tourism competitiveness, facilitate a post-COVID market demand analysis and promote effective utilisation of national governments tourism stimulus packages extended to the tourism sector following the economic downturns. 
The following section outlines the analytical framework. Section three presents the empirical results, and the limitations of this study are discussed in section four. The final section concludes.

\section{The framework of analysis}

This section begins with a review of related work and relevant literature, followed by an outline of the analysis method. A theoretical justification of variable measures is also provided, followed by a discussion of the data sources.

\subsection{Related work}

International travel for leisure and the tourism industry's contribution to a country's longterm development process has been extensively studied. Worldwide, international visitors spend billions of dollars directly in their preferred destinations for leisure, benefitting local economies that have generated nationwide multiplier effects. According to PulidoFernandex, Rodriquez-Diaz and Cardenas-Garcia (2020), several factors determine tourist expenditure, the socio-economic attributes of the tourist, the characteristics of their trip, the activities of the holidaymakers in the destination and the level of satisfaction with the destination.

The world's tourism sector has been a fundamental force shaping globalisation (Song et al. 2017). Several scholars have made valuable theoretical and empirical contributions to the tourism literature. Ozturk (2016) and Tang and Ozturk (2017) thoroughly explained the theoretical and empirical relationship between tourism, development, and growth. Other recent studies such as Calero and Turner (2020), Neuts (2020), Petrei et al. (2020), Contu et al. (2020), Santamaria and Filis (2019), Antolini and Grassini (2019) and Boto-Garcia et al. (2018) have examined the impact of tourism on nations growth and development process, revealing beneficial impacts on international visitor recipient countries. Numerous other scholarly contributions of in the past, for example, Rugg (1973), Dwyer et al. (2000), Divisekera (2003), Tosun et al. (2003), Ozturk and Acaravici (2009), Tribe (2011), Song et al. (2012) have also added significant value to the understanding of the determinants of international tourism.

According to the tourism led growth literature, as reviewed in Tang et al. (2017), there is compelling evidence of many nations realising significant long-term growth. Other than the tourism led growth literature, numerous other studies (for example, Tosun et al. 2003, Calero and Turner 2020; Neuts 2020; and Santamaria and Filis 2019, among others) have revealed tourism to be a significant contributor to several nations' development process. Tourism's primary contribution comes from its foreign exchange earnings, with evidence from the abovementioned studies indicating that tourism has positively impacted the trade sectors (share in total exports) earnings across several countries. The studies mentioned above have concluded that tourism has positively impacted several economies worldwide, including stimulating new economic activities, job creation, income generation, inter-industry linkages, and regional development. In many of the world's highly touristdependent developing countries, its contribution to output and national development has exceeded that in other world regions, as noted in the Caribbean countries (Cannonier and Burke 2019) and several small developing countries in other regions. The potential effects of the tourism sector range from economic growth, social inclusion, and cultural and 
environmental preservation. Comerio and Strozzi (2019) provide a comprehensive review of tourism's potential benefits and detrimental effects.

\subsection{Tourism as a socio-economic value}

The tourism and hospitality sector is one of the advanced service industries in many nations across the globe. This sector has contributed significantly to the economic growth and development of several nations, including the developing, emerging, and small island states. A review of the tourism led growth literature provides ample evidence of the beneficial contribution of tourism to a low and middle-income nation's path towards socioeconomic development, as shown in Gunduz and Hatemi-J (2005); Bonham et al. (2009); Fayissa et al. (2011); and Min, Phoh and Bak (2016).

Other than its role in promoting global connectivity (Song et al. 2017), previous research outcomes such as Brau et al. (2007), Sequira and Nunes (2008), and Min et al. (2016) demonstrated that countries with a large tourism sector recorded robust foreign exchange that contributed to new economic activities, job creation, income generation, inter-industry linkages, cultural exchange and regional development. According to Scheyvens and Russell's (2012), tourism has benefitted households through income generation, job creation and community development. Tourist spending patterns in destination countries has helped a range of small businesses to flourish, directly benefitting the low-income earners.

Other potential beneficial effects of the tourism sector include social inclusion to cultural and environmental preservation. Worldwide and in abundant labour countries, much of the tourism sector is also labour intensive, contributing to the absorption of domestic labour and new job creation. Domestic labour gets easily absorbed in various tourismrelated businesses, including service industries such as accommodation, food and beverage services, transportation, travel agencies, cultural, sporting, and recreational activities. Tourism also contributed to inter-industry linkages within nations production sectors such as agriculture, manufacturing, retail, logistics and transportation and food and beverages.

\subsection{Materials and method}

The improvements in tourism data recording and statistical analysis have elevated understanding of the primary determinants of tourism demand. For example, Crouch and Perdue (2014), Morley et al. (2014), Zhang (2015), and Tavares and Leitao's (2016) empirical findings reveal robust results of the determinants of tourism demand. Much of the past studies have focused primarily on understanding the determinants of tourism from a market demand perspective, revealing three broad categories (demand-driven elements, destination country attributes, and other factors) explaining tourism demand.

The analysis adopted in this study to understand the effect of government stringency on hotel occupancy aligns with the demand-side perspective and adopts the consumer choice model based on the seminal research by Rugg (1973). This is an appropriate framework given that consumers are assumed to maximise their spending on tourism products from their budget and various other taste and preferences of tourism products. Tourists derive their satisfaction (utility) from consuming various tourism products (hotel accommodation, food, recreation and travel, among others). Hence, adopting the consumer choice model becomes relevant as consumers are utility maximisers rendering to the neoclassical consumer demand theory. 
According to the consumer theory, individuals maximise their utility subject to budget constraints (Varian 1978). The consumer choice model captures various aspects of consumers activities that satisfy their needs and want. The basic assumption is that consumers behave rationally and make choices that best suit their travel plans, budget, and preferences, maximising their value. It is also assumed that given the extensive diffusion of information and communications technology, consumers also have access to perfect information on tourism destinations, products and offerings. Thus, it is the consumer's aspect of decision making and spending based on perfect information that the model can explain tourists buying behaviour. Once the model is applied to tourism, it refers to choices by tourists between destinations that can differ in their attributes, such as recreational activities, services and choice of accommodation types. It is with this respect that this model is appropriate and adopted in this study.

The analytical model of choice assumes that individuals are constrained by limited incomes and attempt to achieve the highest utility possible (Nicholson 2005). As noted above, the analytical model in this study assumes visitors maximising their choice of stay in a particular destination by spending their income and time and maximising utility. Assuming a fixed amount of income allocated for leisure, an individual will purchase quantities of goods and services until all the income is spent. Following Nicholson's (2005) general principle of utility maximisation, a visitor's utility maximisation condition is subject to his/her budget constraints in Eq. 1 .

$$
\operatorname{Max} U(H-O, B)
$$

Subject to : $P_{U} \cdot H-O+P_{B} \bullet B=D Y_{U} \cdot H-O+P_{B} \cdot B=D Y$.

Where $U(\cdot)$ is the utility function; $H-O$ is hotel occupancy, a tourist related good and service, $P_{U}$ is the price of $H-O ; B$ is the bundle of all other goods and services; $P_{B}$ is the price of $B ; D Y$ is the total budget (individual's disposable income). Using the Lagrange multiplier to solve the above utility function $U(\cdot)$ in equation one gives the general hotel demand equation two.

$$
H-O=H-O\left(P_{U} P_{B}, D Y\right)
$$

Hotel demand in visitors preferred countries can be influenced by factors other than income. The core variable hypothesised to impact hotel occupancy in destination countries since the COVID-19 pandemic is government stringency measures. The analysis also controls for several other factors to avoid model misspecification. The chosen control variables are the real exchange rates, the relative prices between origin and destination countries, the travel distance between the visitor origin and the destination country, common language and freedom and democratic values in the destination country. The estimable form of the consumer choice model is expressed in equation three, where the $\lambda$ 's indicates the expected effects of each variable.

$$
\begin{aligned}
\ln H-O_{i, t}^{D C}= & \lambda_{0}+\lambda_{1} \ln G S_{i, t}^{O C}+\lambda_{2} \ln Y_{i, t}^{O C-D C}+\lambda_{3}+\lambda_{3} \ln D I S_{i, t}^{D C-O C}+\lambda_{4} \ln P_{i, t}^{O C-D C} \\
+ & \lambda_{5} \ln R E R_{i, t}^{D C}+\lambda_{6} \ln D E M_{i, t}^{D C}+\lambda_{7} \ln L A N_{i, t}^{D C}+\mu_{i, t} \\
& \lambda_{1}\left\langle 0 ; \lambda_{2}\right\rangle 0 ; \lambda_{3}\left\langle 0 ;+\lambda_{4} ? ; \lambda_{5}\left\langle 0 ;+\lambda_{6}\right\rangle 0 ; \lambda_{7}\right\rangle 0
\end{aligned}
$$

In equation three, $\mathrm{H}-\mathrm{O}$ is the hotel occupancy rates of each top ten destination countries (percentages). $D C$ is the destination country, $O C$ is the origin country, $\ln$ is natural logarithim, $t$ is time, $i$ is country, and $\mu$ is the stochastic error term. 
Several empirically oriented studies have emerged in the literature that adopt a choice modelling approach with improved data on a range of countries and regions worldwide that successfully identified the determinants of tourism demand. For example, noteworthy contributions include Bakkal (1991); De Mello et al. (2002); Divisekera (2003); Vogt (2008); Song et al. (2012); and Gatt and Falzon (2014). Research on factors that determine tourism demand across various nations has undoubtedly strengthened over time as previous studies reveal robust results of the determinants of tourism demand such as Gatt and Falzon (2014), Morley et al. (2014), Zhang (2015) and Tavares and Leitao (2016). Sinclair (1998) and Song et al. (2012) give a comprehensive review of demand models for tourism studies.

\subsection{Variable justification and measures}

In Eq. 3, GS is the government stringency, the core variable of interest. It represents the state instituted measures in response to containing the COVID-19 outbreak and transmission. The Oxford COVID-19 Government Response Tracker (OxCGRT) has consistently and systematically tracked, collected and compiled information on twenty-three policy responses (indicators) for 180 countries since the beginning of 2020, detailed in Appendix Table 1. Among these twenty-three indicators, nine are policy indicators recording information on containment and closure policies such as workplace closures, school closures and travel bans. The data are aggregated into indices to reflect government stringency with numerical values ranging from 1 (no restrictions) to 100 (strictest restrictions). The OxCGRT continues to update the policy response indicators. Appendix Table 1 provides a brief description of the twenty-three indicators, while the actual measures of the index and the methodology of aggregation are given in Hale et al. (2021).

$Y$ is the income, measured by the gross domestic product per capita (purchasing power parity, constant 2011 in United States dollars). In the consumer choice models, the incomes of visitors are one of the potential determinants of leisure travel. According to the consumer choice theory, incomes induce people to travel more and demand more tourism goods. Empirical findings of Divisekera (2003), Song et al. (2012) and Fereidouni et al. (2014) provide significant support to the income-travel hypothesis.

$D I S$ is the flight distance from the capitals of the origin and destination countries. Distance is a vital variable in people's intention to travel (Cao et al. 2019), identified as fundamental friction by the gravity model of international trade (Anderson 1979). The argument is that the higher the distance between the visitors' home country and intended destination country for leisure travel, the higher the cost of travel, translating into fewer visitors. On the contrary, a shorter travel distance may mean lower travel costs translating into higher demand for international travel and hotel accommodation.

$P$ is the ratio of consumer prices between the destination and the origin country. Other than visitors' home country business cycle impacting the decision to travel the destination country, costs can matter for visitors' choice of travel. Loeb (1982) stated that tourists make a logical choice to travel by comparing prices between their home country and the holiday destination country and engage in spending if the costs of the selection of country's goods are less than their country of residence.

Variable $R E R$ is the real effective exchange rate index $(2010=100)$. This variable is included with the hypothesis that movements of foreign exchange rates can impact tourists' purchasing power (Ozturk 2006 and Wang 2009). The hypothesis is that depreciation of a country's currency reduces outbound tourism, and an appreciation of a country's currency 
reduces travel costs and induces the demand for foreign travel as travel costs are likely to be less.

DEM is a democracy, captured by the Global Freedom Scores, compiled by the Freedom House, with higher numerical scores representing more freedom. Upholding freedom and democratic values (freedom of expression, law and order, absence of corruption, and civic responsibility) are fundamentally essential for markets. Destination country achievements in these democratic values can influence visitors' choice of holiday destinations. Conversely, the absence of democratic values can deter people's intention to travel for leisure.

$L A N$ is the common language, measured by a dummy variable with 1 for a common language and 0 otherwise.

\subsection{Choice of countries and sources of data}

The choice of the ten countries listed in Table 1 is due to several reasons. The primary factor is that the selected countries had a consistent set of published data on all the variables entering the estimation phase of equation three due to the absence of data on variables of interest as outlined in Eq. 1. Second, this study intends to focus on top visitor destinations only while comparative analysis of other countries not forming part of the top destinations is left for future research. Third, in terms of model estimation, the method adopted in this research required data to be consistent across time and countries for all variables under consideration as the sample countries satisfactorily met this requirement.

The data source for the dependent variable, $\mathrm{H}-\mathrm{O}$, is United Nations World Tourism Organisation (https://www.unwto.org/unwto-tourism-recovery-tracker). GS is sourced from Oxford COVID-19 Government Response Tracker (OxCGRT). The data for flight distance is Prokerala.com (https://www.prokerala.com/travel/airports/distance/from-pek/to-hkg/). The source of data for DEM is Freedom House (https://freedomhouse.org/countries/freed om-world/scores). Finally, the data source for variables $Y, P$, and RER is the World Development Indicators (The World Bank, https://datacatalog.worldbank.org/dataset/worlddevelopment-indicators).

\section{Findings}

Among the sample countries entering the empirical phase, the first glance of government stringency measures and hotel occupancy rates is depicted in Fig. 1. Figure 1 depicts the monthly average scores of government stringency and hotel occupancy rates for the ten visitor destination countries, with data averaged from March 2020 to March 2021. According to Fig. 1, monthly average hotel occupancy rates fell sharply in Germany, Italy and Thailand. During this time, average stringency index values reveal that COVID-19 containment measures varied across the sample countries, with the United Kingdom having the most stringent containment policies while Thailand had the least. China, Germany, Italy and Mexico were other destinations adhering to strong COVVID-19 containment measures with government stringency index scores exceeding 70.0.

The discussion in section two unfolded the core variable of interest together with control variables and outlined the functional form for estimation, represented by equation three. As part of the empirical process, equation three was estimated in the linear and double loglinear forms. The first estimations showed that the double log-linear form produced a more 


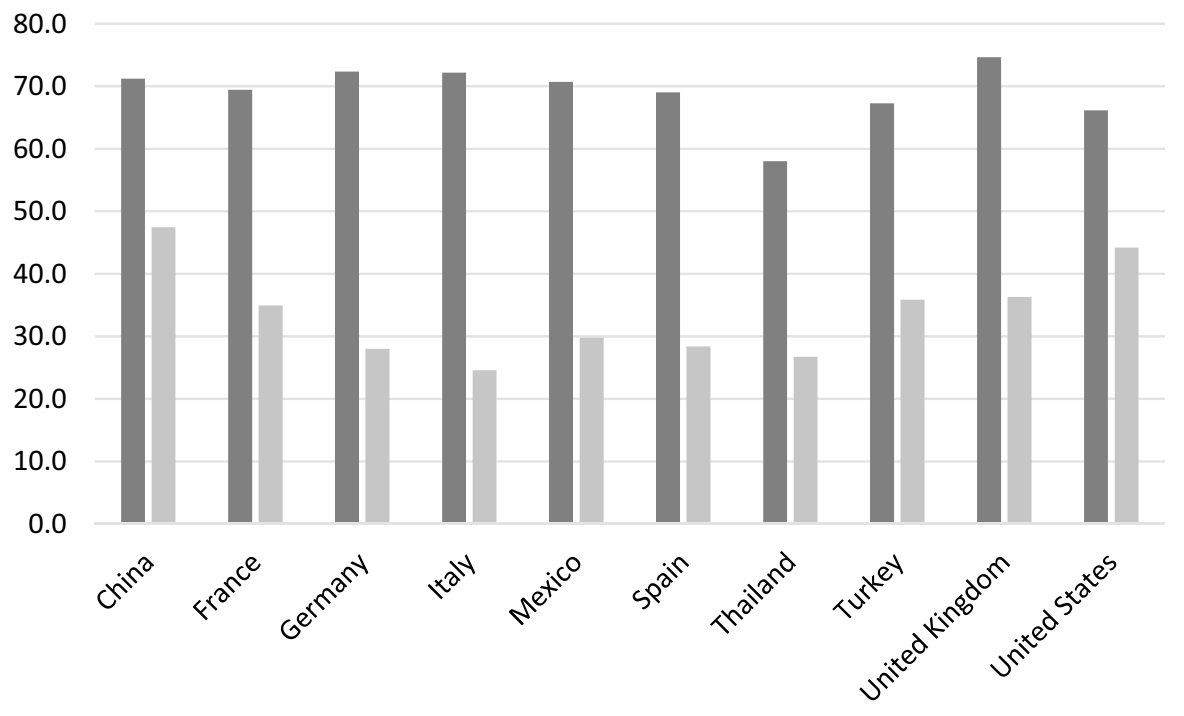

Average Stringency $\square$ Average occupancy

Fig. 1 Average stringency and hotel occupancy rates (March 2020 to March 2021) Source: Authors computations using the OxCGRT data

robust outcome regarding theoretical expectations, statistical significance, and satisfactorily holding up to a range of definitive diagnostic tests. After establishing the functional form, equation three is estimated in several specifications. However, to determine any tangible impact of the prime variable, government stringency effect on hotel occupancy rates as depicted in Fig. 1, the analysis begins by establishing the correlation between these variables. Figure 2 presents the scatter plots, confirming a negative correlation between government stringency and hotel occupancy rates as the data points slope downwards from the upper left of Fig. 2 to the lower right.

Table 2 defines the set of variables used in the estimation phase while Table 3 presents the results of four different estimations through successive control variables (estimations 1 to 3 in Table 3). In estimation 1 (Table 3), the direct effect of government stringency is tested without including the control variables to get an initial assessment of its effect. In estimation 2 (Table 3), two of the commonly used control variables, income, and distance, are added, while estimation 3 (Table 3 ) includes the complete model. Finally, in estimation 4 (Table 3), insignificant variables are dropped to gauge the strength of the significant variables.

\subsection{The effect of government stringency on hotel occupancy rates}

According to estimation 1 in Table 3, the coefficient of government stringency is as per the theoretical expectations. It has the expected negative sign and is statistically significant at the 5 per cent level $(\lambda=-0.710$ and $\rho=0.05)$. Controlling income and distance, the sign on coefficient government stringency remains negative $(\lambda=-0.710)$. It is also statistically significant at the 5 per cent level (estimation 2). Once the complete model is estimated (estimation 3), coefficient government stringency is again as expected, negative $(\lambda=-0.955)$ 


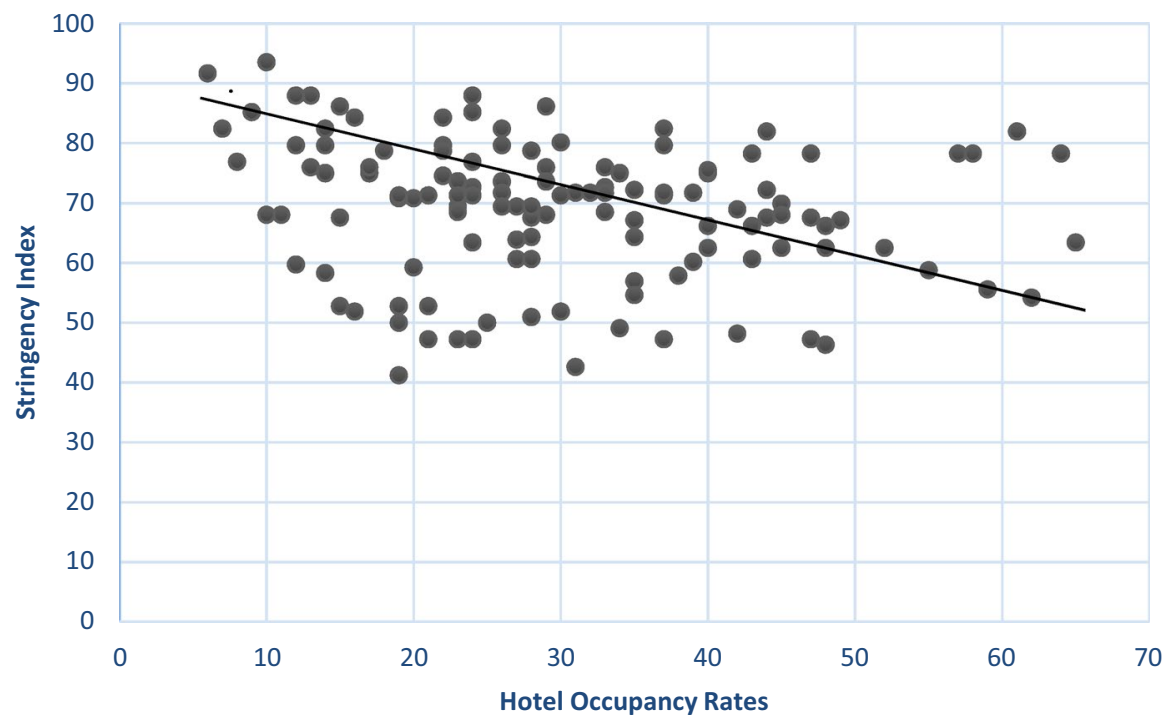

Fig. 2 Government stringency versus hotel occupancy rates relationship Source: Authors computations using the OxCGRT data

with an improved level of statistical significance from estimations 1 and 2 . The results of government stringency improve significantly $(\lambda=-0.710$ to -0.955$)$ and are more robust in their statistical significance once all the control variables are included. Given the inconclusive outcomes for $Y, D$ and $P$ in estimation 3, these variables are dropped. The results of government stringency strengthen further as indicated by the estimated coefficient $(\lambda=-1.007$ and $\rho=0.0)$. The sign on coefficient $G S$ remains negative and statistically significant at the 1 per cent level. The findings for $G S$ in all the estimations reported in Table 3 provides strong empirical evidence to suggest that government stringency had a statistically significant negative effect on hotel occupancy rates in the top ten visitor recipient countries. This finding strongly suggests that the world's top ten visitor recipient countries governments COVID-19 containment measures adversely impacted their tourism hospitality sector with significant drops in visitor arrivals, which led to a significant plunge in hotel occupancy rates.

\subsection{The effect of control variables on hotel occupancy rates}

Regarding the control variables, RER is negative $(\lambda=-0.465$ and $\rho=0.05)$ and statistically significant at the 5 per cent level. This finding strongly suggests that exchange rates between origin and destination countries matter and has an essential role in determining hotel occupancy rates. Coefficient $D E M$ is positive and statistically significant at the 1 per cent level (estimations 3 and 4). This finding provides convincing evidence to support the hypothesis that higher levels of freedom and democratic values are significant destination country attribute that has attracted an increasing number of visitors. It confirms that visitors place a high value in their decision to visit their preferred country based on their freedom and democratic values achievements. Coefficient $L A N$ has the expected positive signs and is statistically significant at the 1 per cent level in estimations 3 and 4 . This finding also 


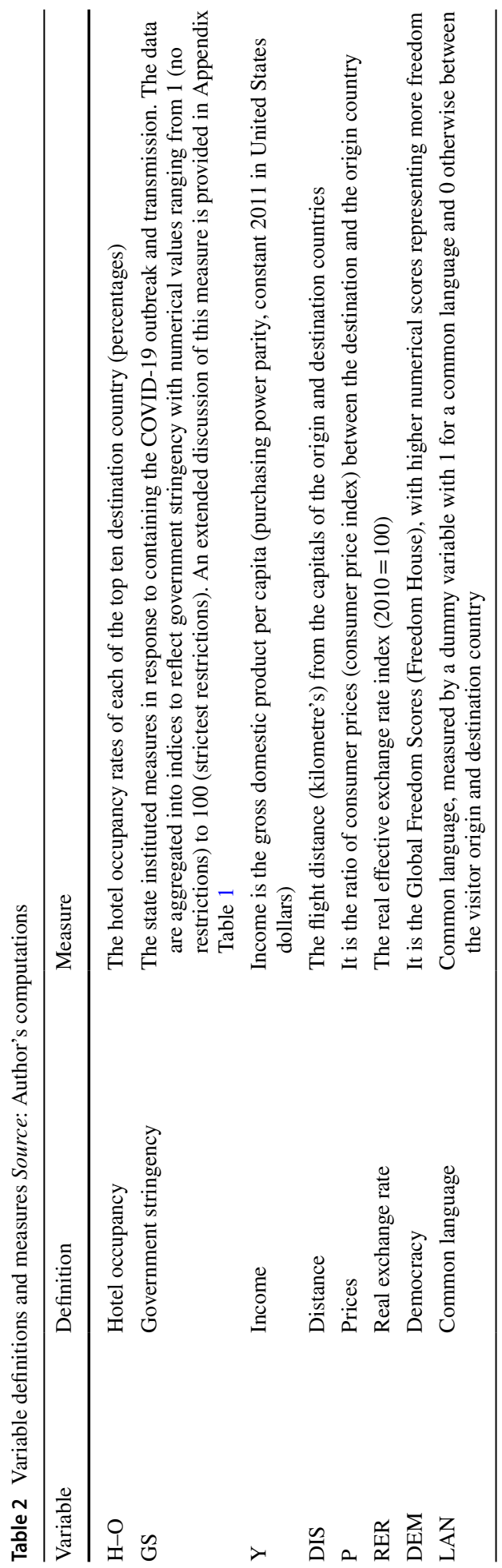


Table 3 Results of government stringency on hotel occupancy rates

\begin{tabular}{|c|c|c|c|c|}
\hline Variables & Estimation 1 & Estimation 2 & Estimation 3 & Estimation 4 \\
\hline Constant & $\begin{array}{l}6.279 \\
(5.428)^{*}\end{array}$ & $\begin{array}{l}5.852 \\
(3.804)^{*}\end{array}$ & $\begin{array}{l}6.00 \\
(3.445)^{*}\end{array}$ & $\begin{array}{l}7.651 \\
(6.706)^{*}\end{array}$ \\
\hline$(\ln ) G S$ & $\begin{array}{l}-0.710 \\
(2.583)^{* *}\end{array}$ & $\begin{array}{l}-0.607 \\
(2.135)^{* *}\end{array}$ & $\begin{array}{l}-0.955 \\
(3.618)^{*}\end{array}$ & $\begin{array}{l}-1.007 \\
(3.555)^{*}\end{array}$ \\
\hline$(\ln ) Y$ & & $\begin{array}{l}-0.051 \\
(0.806)\end{array}$ & $\begin{array}{l}-0.088 \\
(1.348)\end{array}$ & \\
\hline$(\ln ) D I S$ & & $\begin{array}{l}0.067 \\
(1.337)\end{array}$ & $\begin{array}{l}0.185 \\
(3.315)^{*}\end{array}$ & \\
\hline$(\ln ) P$ & & & $\begin{array}{l}-0.063 \\
(0.116)\end{array}$ & \\
\hline (ln)RER & & & $\begin{array}{l}-0.465 \\
(1.960)^{* *}\end{array}$ & $\begin{array}{l}-0.357 \\
(3.783)^{*}\end{array}$ \\
\hline$(\ln ) D E M$ & & & $\begin{array}{l}0.681 \\
(4.389)^{*}\end{array}$ & $\begin{array}{l}0.333 \\
(2.712)^{*}\end{array}$ \\
\hline (ln) $L A N$ & & & $\begin{array}{l}2.090 \\
(6.020)^{*}\end{array}$ & $\begin{array}{l}1.501 \\
(4.655)^{*}\end{array}$ \\
\hline$N$ & 130 & 130 & 130 & 130 \\
\hline$F$ & 8.5 & 3.75 & 9.46 & 13.3 \\
\hline $\operatorname{Adj} . R^{2}$ & 0.06 & 0.08 & 0.35 & 0.30 \\
\hline LM test & 20.9 & 19.8 & 31.1 & 30.3 \\
\hline$B-P$ test & 96.2 & 105.8 & 101.7 & 90.1 \\
\hline SSE & 30.8 & 30.15 & 21.2 & 22.9 \\
\hline$G C V$ & 0.24 & 0.25 & 0.19 & 0.19 \\
\hline$D-W$ & 0.88 & 0.85 & 0.95 & 0.99 \\
\hline$J-B$ & 4.3 & 5.18 & 11.3 & 10.9 \\
\hline
\end{tabular}

$(l n)$ is natural logarithm; $N$ indicates the number of observations; $F$ is the F-statistics; $A d j . R^{2}$ is the adjusted R-square; $L M$ test is the test for cross-sectional heteroskedasticity ( $\chi^{2} 9$ d.f.); $B-P$ test is the BreuschPagan test for diagonal covariance matrix ( $\left(\chi^{2} 45\right.$ d.f.); SSE is the sum of squared errors; $G C V$ is generalised cross-validation, and $D-W$ is the Durbin-Watson statistics. $J-B$ is the Jarque Bera test for normality. $(*)$, $(* *)$ and $(* * *)$ indicate statistically significant at the 1,5 and 10 percent levels, respectively. (...) indicates variable, not assessed

confirms that common language is a significant variable determining the travel decisions of tourists. Finally, variable $P$ was included to capture costs between living in the destination country relative to the visitor's home country. The findings show that the coefficient $P$ while having the expected negative sign, is statistically insignificant. Hence, relative prices weakly determine hotel occupancy rates.

\subsection{The value of this analysis}

Based on the consumer choice modelling approach, the empirical results and the discussion above have satisfactorily captured the effects of government stringency, among other factors determining hotel occupancy rates in the world's major tourist destination countries. 
The findings of this study reveal that higher levels of government stringency are a crucial predictor of hotel occupancy rates in the top ten tourist destination countries. The findings confirm that while early approaches to interventions by the government enforcing strict measures is likely to have dampened the transmission of COVID-19 in the short run, stringent government interventions had adversely impacted hotel occupancy rates. Although past research has provided insights into the potential determinants of hotel occupancy rates among different visitor destination countries, much of the previous and recent empirical works have focused on standard determinants between visitor origin and destination countries. In contrast, research has been deficient in empirically testing restrictive government measures in response to the pandemic on hotel occupancy rates within the local and global context. By including the newly developed government stringency measure, the modelling approach adopted in this study has elevated the analytical modelling approach beyond the standard confines of the consumer choice models.

\section{Limitations}

The study has limitations regarding the model's application as it is limited to using a nonrandom sample. The selection of countries is driven by the availability of data, which makes the analysis restrictive, so this may not be considered a random selection. Other influences such as demographics and hotel and accommodation attributes may influence individual travellers to make choices of hotels that the model does not capture.

The sample countries in the model are also a limitation. It only includes the top ten tourist destinations worldwide and does not compare to other less favourable destinations and how consumers would choose various destinations for their visit. The model does not attempt to capture any of the mediating factors among the predictors as, theoretically, this may be possible.

Finally, while the government stringency measure comprised nine indicators (see "Appendix" Table 1) and while this is a valuable measure, the estimations did not analyse the level of variation in the implementation of the individual nine indicators that contributed to the aggregate level of government stringency. Once a more extensive data set covering more years of stringency becomes available, future research is encouraged to address this issue, extend the sample of countries and other preferred destinations, provide geographically regional comparisons, and consider modelling the mediating factors among the predictor variables. 


\section{Conclusions and outlook}

The transmission of COVID-19 across the world has caused unprecedented damage to the world's economy from 2020 to date. International tourism has been one of the worst affected economic sectors of the world economy due to bans on international travel, border closures, closure of public places and advice of governments against travel due to the outbreak and the accelerated transmission of COVID-19. As a result, this sector bears a significant brunt of the pandemic than others.

The direct effects of the COVID-19 pandemic inspired government stringency on hotel occupancy rates in the world's top ten visitor recipient countries was the subject of investigation. Using the recently established novel indicator of government stringency from The Oxford COVID-19 Government Response Tracker database, the empirical results based on the consumer choice modelling framework revealed a statistically significant adverse effect of government stringency on hotel occupancy rates. The empirical findings also confirmed exchange rates, freedom and democratic values and common language as other significant influences having a pivotal role in shaping hotel occupancy rates. The findings based on the consumer choice modelling framework has unfolded the effect of government stringency on hotel occupancy rates.

The findings confirm the importance of the consumer choice modelling analytical framework, which is highly relevant to international tourism studies. The consumer choice modelling framework has successfully captured the effects of government stringency on hotel occupancy rates and further improves the understanding of the potential influences in hotel occupancy rates. The findings conclude that while governments worked effectively through regulations and policies to contain COVID-19 with the containment measures having the desired effects of reducing transmissions of COVID-19, such measures have adversely impacted the tourism industry. As a result, government stringency has contributed to severe economic repercussions to the tourism hospitality sector with reduced demand for hotel accommodation as occupancy rates plunged. It should be noted that this study is data-driven, primarily influenced by the government and its institutions. However, such data can be used to evaluate government actions that, in turn, unlock the potential of formal data to make informed decisions. Hence, using formal data for determination and making informed decisions is critical instead of acting without reliable data that can possibly contribute to ineffective outcomes.

In terms of the outlook of the hotel and hospitality sector, there is a growing momentum of some optimism. The development of COVID-19 vaccines and the start of the inoculation of populations worldwide against COVID-19 is driving towards a gradual reduction in international travel restrictions and raises tourists' confidence about future travel plans with the confidence of recovery in the hotel sector the tourism industry. There are vital signs that international travel will normalise in the medium to long term as several countries worldwide are gradually and temporarily resorting to opening their 
borders. Nevertheless, visitor movements at present remain many times below the preCOVID-19 levels.

It can be predicted that any significant pick-up in visitor movements across the major tourist destination countries will depend upon home and source countries speed of vaccinations against the COVID-19 and the relaxation and stringency of the COVID-19 containment measures. At the same time, there is growing evidence that many of the significant international visitor sources and recipient countries such as the United Kingdom and parts of Europe are experiencing sudden and rapid rises in COVID-19 infection rates driven by the relaxation of stringency measures. The newly identified potentially more transmissible COVID-19 variant (Omicron) in November 2021 poses a significant threat and challenges that could lead to increased government stringency measures in the short run. Therefore, there are chances that any anticipated quick recovery in hotel occupancy rates can be fraught with obstacles of sudden lockdowns that can dampen any optimism that emerges in the short run. However, as the COVID-19 situation has gotten better in some countries, governments can start allowing tourists to come from those countries on a smaller scale and with preventative measures that reduce transmission rates of COVID-19 while reviving the tourism and hotel industries.

The short-term outlook of the global tourism and hospitality sectors (given that many countries are hesitant to loosen tourism restrictions rapidly) means that the tourism and hotel sectors recovery looks elusive for most of 2022. While some countries promoted domestic tourism through strategies such as creating domestic and partner country travel bubbles, the recovery has been minimal and not close to the pre-pandemic levels.

Another development that has taken place since the launch of the COVID vaccines in late 2020 is that countries around the world have started to introduce "vaccine passes gradually". Although this gives some optimism towards the recovery of the tourism and hospitality sector, there are significant challenges ahead for vaccine passes. Vaccine effectiveness, its duration in providing immunity and restraining onward transmission of the disease are issues that do not provide a high degree of confidence amongst policymakers in many countries to normalise travel to pre-pandemic levels. In addition, the current global inequities in vaccination rates and several visitor origins and destination countries are a concern that adds further friction to the recovery of the tourism sector. Finally, there is an absence of uniformity in verifying vaccine passes and recognition of its authenticity and the absence of a global agreement on a universal protocol for vaccine recognition given a range of vaccines used across different countries with varied efficacy rates.

\section{Appendix}

See Table 4 


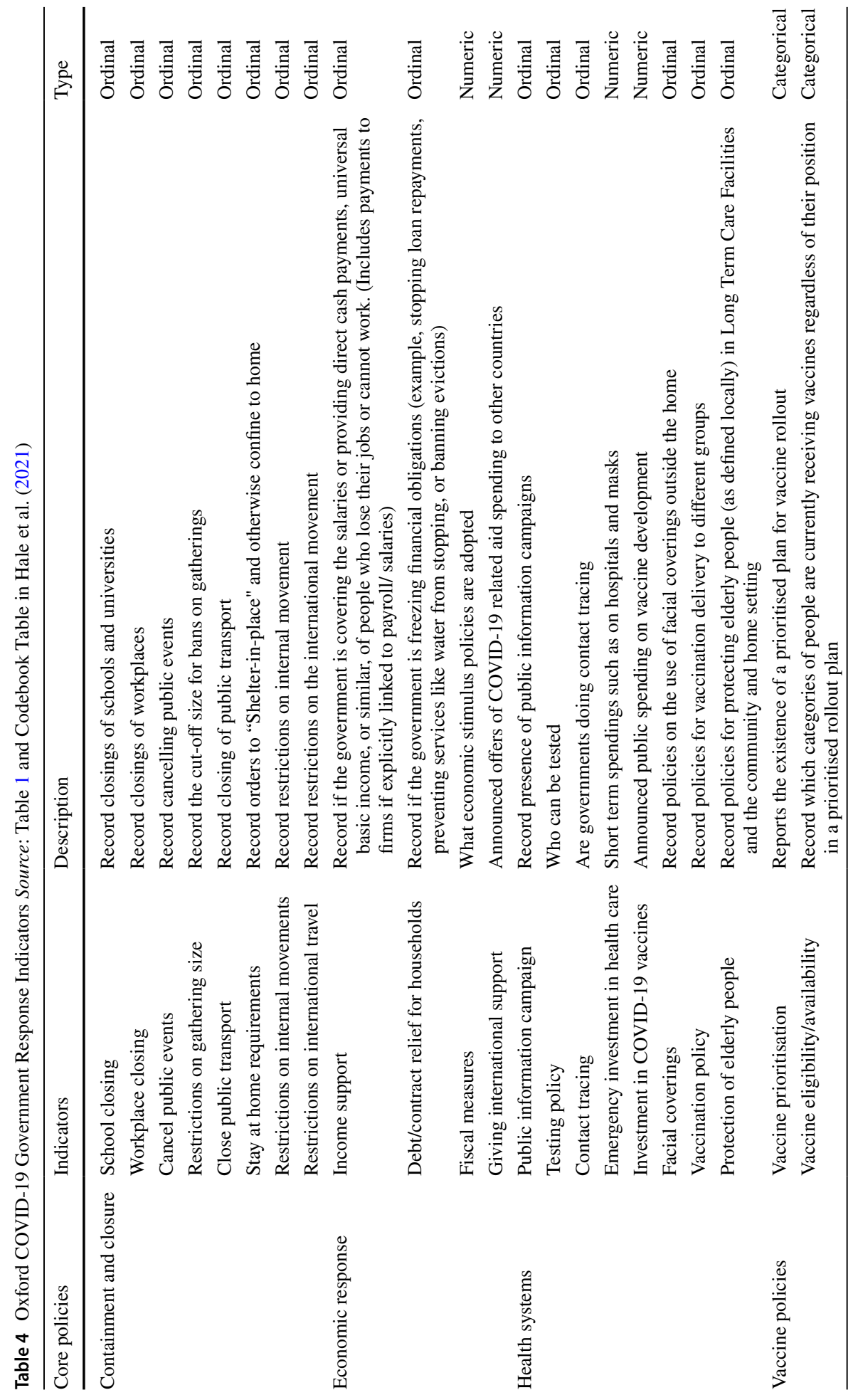




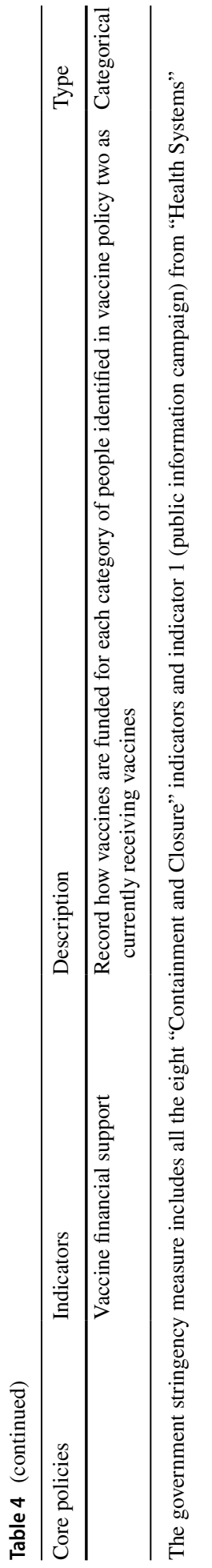

Din Springer 
Acknowledgements The author expresses sincere gratitude to two anonymous reviewers for their insightful comments on an earlier draft.

Funding There was no funding for this paper from any source.

\section{Declaration}

Conflict of interest The author declares that there is no conflict of interest.

Ethical approval This research did not involve any human or animal subjects and therefore no ethical approval was sought nor was any informed consent required.

\section{References}

Anderson, J.E.: A theoretical foundation for the gravity equation. Am. Econom. Rev. 69, 106-116 (1979)

Antolini, F., Grassini, L.: Foreign arrivals nowcasting in Italy with Google trends data. Qual. Quant. 53, 2385-2401 (2019)

Bakkal, I.: Characteristics of West German demand for international tourism in the Northern Mediterranean region. Appl. Econ. 23, 295-304 (1991)

Barro, R. J., Ursúa, J. F., \& Weng, J. (2020). The coronavirus and the great influenza pandemic: Lessons from the "Spanish flu" for the coronavirus's potential effects on mortality and economic activity (NBER Working Paper No. 6866). National Bureau of Economic Research.

Bonham, C., Gangnes, B., Zhou, T.: Modelling tourism: a fully identified VECM Approach. Int. J. Forecast. 25, 531-549 (2009)

Boto-Garcia, D., Benos-Pino, J.F., Alvarez, A.: Determinants of tourists length of stay: a hurdle count data approach. J. Travel Res. 58(6), 977-994 (2018)

Brau, R., Lanza, A., \& Pigliaru, F.: How fast are small tourism countries growing? Evidence from data for 1980-2003, Tour. Econ. 13, 603-613 (2007)

Calero, C., Turner, L.W.: Regional economic development and tourism: a literature review to highlight future directions for regional tourism research. Tour. Econ. 26(1), 3-26 (2020)

Cao, J., Zhang, J., Wang, C.: How far is the ideal destination? Distance desire, ways to explore the antinomy of distance effects in the tourist destination choice. J. Travel Res. 59(4), 614-630 (2019)

Cannonier, C., Burke, M.G.: The economic growth impact of tourism in small island developing states evidence from the Caribbean. Tour. Econ. 25(1), 85-108 (2019)

Chen, G., Cheng, M., Edwards, D. \& Xu, L. (2021). COVID-19 pandemic exposes the vulnerability of the sharing economy: a novel accounting framework, J. Sustain. Tourism, 1-18.

Comerio, N., Strozzi, F.: Tourism and its economic impact: a literature review using bibliometric tools. Tour. Econ. 25(1), 109-131 (2019)

Costantino, V., Heslop, D. J., \& MacIntyre, C. R. (2020). The effectiveness of full and partial travel bans against COVID-19 spread in Australia for travellers from China during and after the epidemic peak in China, Journal of Travel Medicine, 27(5), taaa081.

Contu, G., Conversano, C., Frigau, L., Mola, F.: Identifying factors affecting the status of super host: evidence from Sardina and Sicily. Qual. Quant. 54, 1633-1653 (2020)

Crouch, G.I., Perdue, R.R.: The disciplinary foundations of tourism research: 1980-2010. J. Travel Res. 54, 563-577 (2014)

De Mello, M., Pack, A., Sinclair, M.T.: A system of equations model of UK tourism demand in neighbouring countries. Appl. Econ. 34, 509-521 (2002)

Divisekera, S.: A model of demand for international tourism. Ann. Tour. Res. 30, 31-49 (2003)

Dwyer, L., Forsyth, P., Rao, P.: The price competitiveness of travel and tourism: a comparison of 19 destinations. Tour. Manage. 21, 9-22 (2000)

Fayissa, B., Nsiah, C., Tadesse, B.: Research note: tourism and economic growth in Latin American countries - further empirical evidence. Tour. Econ. 17, 1365-1373 (2011)

Fereidouni, H.G., Al-Mulali, U., Mohammed, M.A.H.: Wealth effect from real estate and outbound travel demand: the Malaysian case. Curr. Issue Tour. (2014). https://doi.org/10.1080/13683500. 2014.882886

Gatt, W., Falzon, J.: British tourism demand elasticities in the Mediterranean Countries. Appl. Econ. 46, 3548-3561 (2014) 
Gunduz, L., Hatemi-J, A.: Is the tourism-led growth hypothesis valid for Turkey? Appl. Econ. Lett. 12, 499-504 (2005)

Hale, T., Anania, J., Angrist, N., Boby, T., Cameron-Blake, E., Di Folco, M., Ellen, L., Goldszmidt, R., Hallas, R., Kira, B., Luciano, M., Majumdar, S., Nagesh, R., Petherick, A., Phillips, T., Tatlow, H., Webster, S., Wood, A., and Zhang, Y. (11 June 2021). Variation in Government Responses to COVID-19, Version 12.0, Blavatnik School of Government Working Paper. Available: www.bsg. ox.ac.uk/covidtracker

International Monetary Fund. (April 2021). World Economic Outlook - Managing Diverging Recoveries, Washington, D.C.

Koo, J.R., Cook, A.R., Park, M., Sun, Y., Sun, H., Lim, J.T., Tam, C., Dickens, B.L.: Interventions to mitigate the early spread of SARS-CoV-2 in Singapore: a modelling study. The Lancet 20, 678-688 (2020)

Lim, G., Nguyen, V., Robinson, T., Tsiaplias, S., Wang, J.: The Australian economy in 2020-21: The COVID-19 pandemic and prospects for economic recovery. Australian Econom Rev 54, 5-18 (2021)

Loeb, P.D.: International travel to the United States: econometric evaluation. Ann. Tour. Res. 9, 7-20 (1982)

Maier, B.F., Brockmann, D.: Effective containment explains sub-exponential growth in recent confirmed COVID-19 in China. Science 368(6492), 742-746 (2020)

Min, C.-K., Roh, T.-S., Bak, S.: Growth effects of leisure tourism and the level of economic development. Appl. Econ. 48, 7-17 (2016)

Morley, C., Rosell, J., Santana-Gallego, M.: Gravity models for tourism demand: theory and use. Ann. Tour. Res. 48, 1-10 (2014)

Neuts, B.: Tourism and urban economic growth: a panel analysis of German Cities. Tour. Econ. 26(3), 519-527 (2020)

Nicholson, W.: Microeconomic theory: basic principles and extensions, 9th edn. Thomson-Southwestern, Ohio (2005)

Osseni, I.A.: COVID-19 pandemic in sub-Saharan Africa: preparedness, response, and hidden potentials. Trop Med Health 48(1), 1-3 (2020)

Ozturk, I.: The COVID-19 pandemic and waste management. Duzce Med J 23(1), 27-29 (2021)

Ozturk, I.: The relationships among tourism development, energy demand and growth factors in developed and developing countries. Int J Sust Dev World 23(2), 247-261 (2016)

Ozturk, I., Acaravici, A.: On the causality between tourism growth and economic growth: empirical evidence from Turkey. Transylvanian Rev Administrative Sci 5(25), 73-81 (2009)

Ozturk, I.: Exchange rate volatility and trade: a literature survey. Int. J. Appl. Econ. Quant. Stud. 3(1), 85-102 (2006)

Petrei, F., Cavallo, L., Santoro, M.T.: Cultural tourism: an integrated analysis based on official data. Qual. Quant. 54, 1705-1724 (2020)

Pileggi, S.F.: Life before COVID-19: how was the World actually performing? Qual. Quant. 55, 18711888 (2021)

Pulido-Fernández, J.I., Rodríguez-Díaz, B., Cárdenas-García, P.J.: Key factors of tourism expenditure in emerging urban-cultural destinations. Anatolia 31(1), 31-49 (2020). https://doi.org/10.1080/13032917. 2019.1691615

Rugg, D.: The choice of journey destinations: a theoretical and empirical analysis. Rev Econom Statistics 20, 64-71 (1973)

Santamaria, D., Filis, G.: Tourism demand and economic growth in Spain: new insights based on the yield curve. Tour. Manage. 75, 447-459 (2019)

Scheyvens, R., Russell, M.: Tourism and poverty alleviation in Fiji: comparing the impacts of small- and large-scale tourism enterprises. J. Sustain. Tour. 30(3), 417-436 (2012)

Sequeira, T.N., Nunes, P.M.: Does tourism influence economic growth? A dynamic panel data approach. Appl. Econ. 40, 2431-2441 (2008)

Sinclair, M.T.: Tourism and economic development: a survey. J. Dev. Stud. 34, 1-51 (1988)

Song, H., Li, G., Cao, Z.: Tourism and economic globalisation: an emerging research agenda. J. Travel Res. 57, 999-1011 (2017)

Song, H., Dwyer, L., ZhengCao, G.L.: Tourism economics research. Ann. Tour. Res. 39, 1653-1682 (2012)

Tang, C.F., Ozturk, I.: Is tourism a catalyst of growth in Egypt? Evidence from granger non-causality and generalised variance decomposition analysis. Anatolia 28(2), 173-181 (2017)

Tang, C.F., Cheam, C.L., Ong, S.C.: Comparing the contributions of tourism and non-tourism exports to economic growth in Malaysia. Curr. Issue Tour. 20(12), 1232-1245 (2017)

Thirumaran, K., Mohammadi, Z., Pourabedin, Z., Azzali, S., \& Sim, K. (2021). COVID-19 in Singapore and New Zealand: Newspaper portrayal, crisis Management, Tourism Management Perspectives, 38, 100812 . 
Tosun, C., Dallen, J.T., Yuksel, O.: Tourism Growth, national development and regional inequality in Turkey. J. Sustain. Tour. 11(29), 133-161 (2003)

Tavares, J. M. and Leitao, N. C. (2016). The determinants of international tourism demand for Brazil, Tourism Economics, DOI: https://doi.org/10.5367/te.2016.0540.

Tribe, J. (2011). The Economics of Recreation, Leisure and Tourism, Oxford: Butterworth-Heinemann

United Nations Conference on Trade and Development. (March 31, 2021). Impact of COVID-19 pandemic on trade and development. Retrieved on 19 May 2021 from https://unctad.org/programme/covid-19response/impact-on-trade-and-development-2021

Varian HR 1978 Microeconomic Analysis, New York. W. W. Norton. Vogt,

Wang, Y.S.: The impact of crisis events and macroeconomic activity on Taiwan's international inbound tourism demand. Tour. Manage. 30, 75-82 (2009)

Zhang, A., Zhong, L., Xu, Y., Wang, H., Dang, L.: Tourist's perception of haze pollution and potential impacts on travel: re-shaping the features of tourism seasonality in Beijing. Sustainability 7, 23972414 (2015)

Publisher's Note Springer Nature remains neutral with regard to jurisdictional claims in published maps and institutional affiliations. 